\title{
Coagulation Studies in Extremely Premature Infants
}

\author{
DOROTHY R. BARNARD, MICHAEL A. SIMMONS, AND WILLIAM E. HATHAWAY \\ Department of Pediatrics, University of Colorado Medical Center, Denver, Colorado, USA
}

\section{Summary}

Evidence of developmental evolution of coagulation can be seen when the studies of 10 thriving extremely premature (EPT) infants are compared to normal full-term (FT) infants. The prothrombin time, partial thromboplastin time, and thrombin time all became shorter with increasing gestational age. Fibrinogen levels and platelet counts appear to be comparable to term infant and adult levels. Fibrin degradation products (FDP) of $10 \mu \mathrm{g} / \mathrm{ml}$ or less were found in the thriving EPT infants. When compared to healthy fullterm infants, there is a definite gestational dependency of antithrombin III levels. Factors II and VII appear to be related to intrauterine maturation after the age of viability ( $24 \mathrm{wk}$ ), but factor VII-X complex does not. The contact factors XI, XII, high molecular weight kininogen (Fitzgerald factor), and prekallikrein (Fletcher factor) are all markedly decreased in thriving EPT infants. The mean factor $V$ level is lower than that found in FT infants. This study confirms a gestational age dependency of factor VIII activity. The ratio of factor VIII antigen to factor VIII clotting activity is increased ( $2.8 \mathrm{vs} 1.01$ in FT and adults). Thriving small for gestational age (SGA) infants had coagulation studies which were not statistically different from those of thriving EPT infants. The coagulation changes which occurred in severely ill EPT were mainly in the factors which decrease during intravascular coagulation (factors I, V, and VIII). The present study suggests that because of the high antigen to activity ratio seen in thriving EPT infants, a dysfunctional or fetal factor VIII may have been produced. However, the further elevation of this ratio in the severely ill EPT infants is in keeping with a pathologic proteolysis or increased endothelial release of factor VIII antigen.

\section{Speculation}

Prevention of and prompt therapeutic intervention for asphyxia, sepsis, hypovolemia, hypotension, hypothermia, hypoxia, and acidosis may prevent the occurrence of the coagulation changes seen in the severely ill EPT infants. A distinction between abnormal proteolysis versus production of dysfunctional proteins is essential before specific therapies can be designed.

The prognosis of infants with extreme prematurity (gestational age of 24-31 wk) has improved significantly over the past $10 \mathrm{yr}$. However, complications of hemostasis and thrombosis still contribute to the morbidity of these infants. Difficulties in the diagnosis and therapy of these problems have arisen because of lack of data on the physiologic values of coagulation studies in this age group. In such a high risk population of prematures, obtaining a significant number of physiologically stable infants to study is challenging. Essentially, no published studies of carefully selected normal extremely premature infants are available for comparison.

In this paper, the results of coagulation measurements in a carefully selected group of thriving EPT are compared to those of moderately or severely ill babies of the same gestational age, and to those of normal term infants.

\section{MATERIALS AND METHODS}

Thirty infants born at the University of Colorado Medical Center (UCMC) during the period from November 1976 to January 1978 were studied. The selection of infants for study was determined by the availability of one of the authors (D. R. B.), parental informed consent, and the successful placement of an umbilical catheter. The infants included represent $44 \%$ of all inborn infants less than or equal to $31 \mathrm{wk}$ of gestational age admitted to the UCMC neonatal intensive care during the time period of the study. The mortality rate of infants not selected was $40 \%$ compared to $33 \%$ in those included, the average gestational age was 28 wk compared to $29 \mathrm{wk}$, and the average birth weight was $1032 \mathrm{~g}$ compared to $1005 \mathrm{~g}$. All deliveries were attended by the high risk team which is composed of a neonatologist, a housestaff member on duty in the intensive care nursery, and a neonatal intensive care nurse. Resuscitation included careful attention to prevention of hypothermia, early intervention with respiratory support, and umbilical artery catheter placement. All infants received vitamin $K$ (Aquamephyton) in a dose of $0.5-1.0$ $\mathrm{mg}$ im within $30 \mathrm{~min}$ of birth.

Gestational age was calculated from the mother's expected date of confinement. If it agreed within 2 wk of the clinical assessment (Lubchenco) (9), the gestational age determined by the mother's date of confinement was used. If the estimated gestational age was 3 or more wk different than the mother's dates, the clinical assessment was used to assign a gestational age. No infant had a clinical assessment of greater than $31 \mathrm{wk}$ of gestational age. The 30 infants were divided into thriving (10 infants), unwell (12 infants), or severely ill ( 8 infants) groups. These categories were assigned after an assessment of their early hospital course, but without knowledge of their coagulation results. All infants were scored for four clinical features at the time blood was taken for the studies (see Table 1).

Group 1: Thriving EPT infants had a birth weight appropriate for gestational age, an Apgar score at $5 \mathrm{~min}$ of 7 or greater, and a clinical assessment score of 0 to 1 . All these infants were in good clinical condition at the time of testing and had uneventful hospital courses.

Group 2: Moderately ill EPT infants which had an Apgar score at 5 min less than 7, clinical assessment score greater than 1, or were assessed as SGA. SGA was defined as a birth weight less than the 10th percentile of an intrauterine growth curve (Lubchenco) (39).

Group 3: Severely ill EPT infants who died within $95 \mathrm{hr}$ of postnatal age and had a clinical assessment score greater than 3 (with one exception).

Group 4: Twenty-four normal term infants of 37-41 wk of gestation delivered vaginally after normal uncomplicated pregnancies were studied. In this group, blood was collected into plastic syringes by sterile technique from the umbilical vein of the cord which was doubly clamped before placental separation. Two $\mathrm{ml}$ of blood were drawn through an 18-gauge needle into a plastic syringe and discarded. Through the same needle $1 \mathrm{ml}$ of blood 
Table 1. Clinical scoring used to assess the status of each infant at time of study

\begin{tabular}{lccc}
\hline \multicolumn{1}{c}{ Points } & 0 & 1 & 2 \\
\hline $\mathrm{pH}$ & $\geq 7.30$ & $<7.30>7.20$ & $\leq 7.20$ \\
Peripheral circulation & Good B.P.' $>40$ & Decreased or B.P. ${ }^{\prime}<40$ & Decreased with B.P. ${ }^{\prime}<34$ \\
pO. $^{2}$ & $\geq 50$ & $<50>40$ & $<40$ \\
Respirator pressure & $0-20$ & $21-24$ & $\geq 25$ \\
\hline
\end{tabular}

${ }^{1}$ B.P. $=$ blood pressure.

was collected into a dry syringe and then $9 \mathrm{ml}$ of blood drawn into a third syringe containing $1 \mathrm{ml}$ of buffered citrate solution. Blood was processed as will be described in the EPT infants.

The EPT infants had blood collected for study at a mean age of $40 \mathrm{~min}$ (range $20-90 \mathrm{~min}$ ) except for cases, 1, 22, and 24 from whom blood was drawn at approximately $3 \mathrm{hr}$ of age. All blood was collected from umbilical arterial catheters. Except for cases 1 , 22 , and 24 , the blood used for study was the first blood obtained after clearing the saline filled catheter. Heparin was not used during placement of the umbilical arterial catheter. Blood from cases 1,22 , and 24 was drawn after carefully clearing the catheter to ensure no contamination from heparin used in flush solutions. The blood taken for studies was immediately replaced by heparinized cord blood or citrated bank blood. No infant received heparinized blood before the collection of blood for coagulation studies.

One $\mathrm{ml}$ of blood was drawn into a dry plastic syringe. One-half of this blood was placed in a glass tube for antithrombin III antigen levels and one-half into a glass tube containing Trasylol to be used for FDP determinations. Thrombin ( 2 units) was added to the latter tube to ensure complete clotting. The remainder of the sample was drawn directly into a second syringe containing buffered citrate solution (one volume of citrate for nine volumes of blood). The mean central hematocrit in these infants was $45 \%$ (mode 44\%, range 37-53\%). Only two infants had a hematocrit of greater than $50 \%$. The optimal citrate to blood ratio for the $37 \%$ hematocrit is $1.1: 8.9$, for $43 \% 1: 9$, for $50 \%$ 0.9:9.1. Blood obtained in the glass tubes was allowed to clot $2 \mathrm{hr}$ in a $37^{\circ} \mathrm{C}$ waterbath, then the serum was removed and frozen. Anticoagulated blood was immediately centrifuged at $4^{\circ} \mathrm{C}(2000 \mathrm{~g})$ for $20 \mathrm{~min}$ to obtain platelet poor plasma. The coagulation studies were performed by the Pediatric Hematology Laboratory at UCMC. Plasma for prothrombin time (PT), kaolin partial thromboplastin time (PTT) (53), thrombin time (TT) (62), fibrinogen (56), and antithrombin III-heparin cofactor activity (AT-III) (40) was assayed immediately by established methods. FDP were measured by the latex agglutination technique (Thrombo-Wellcotest, Wellcome Reagents Division, Burrough's Wellcome Company, Research Triangle Park, NC 27709). Platelet counts were done in the routine hematology laboratory by Coulter counter or phase contrast microscopy. Procoagulant activity of the various clotting factors was assayed on frozen samples stored at $-60^{\circ} \mathrm{C}$. Factor II (29), V (8), VII-X (51), and IX (25) were measured as previously described. The clotting activities of factors XI, XII, prekallikrein (Fletcher factor), and high molecular weight kininogen (Fitzgerald factor) were measured using a kaolin PTT method with substrate plasma from cogenitally deficient donors. Factor VII was assayed by a PT method using plasma from a patient with severe factor VII deficiency (28); fibrinogen (factor I) by a heat precipitation method (56) and factor VIII by both a PTT method (1) and a thromboplastin generation time (TGT) method (52). Immunologic assays were performed for factor VIII related antigen (VIII ag) (36) and AT-III antigen (23).

The unpaired $t$ test was used to assess statistical significance.

\section{RESULTS}

A brief clinical description of all preterm infants and their mothers is given in Table 2. Maternal complications did not influence the group in which the infant was placed. Twenty-one of the 30 infants received antibiotics from the lst day of life. Cultures routinely taken before initiation of antibiotic therapy (blood, urine obtained by suprapubic aspiration, tracheal aspirate, plus spinal fluid when done) were negative in all infants studied. Twelve mothers were on antibiotics at the time of delivery (one was the mother of twins).

Autopsy results on the infants who died are shown in Table 3. The results of coagulation studies are given in Table 4 . These results are compared to those obtained for healthy FT infants 37 41 wk of gestation and normal adults. The PT, PTT, and TT were significantly prolonged in group 1 compared to term infants $(P$ $=<0.01)$. However, their platelet counts and fibrinogen levels were comparable to FT and adult values. The vitamin K-dependent factors II and VII were significantly lower in group $I$ than term infants. There was no difference noted when group $I$ and FT plasmas were assayed for VII-X complex. Only three thriving EPT infants had factor IX levels measured. The contact factors (XI, XII, high molecular weight kininogen, and prekallikrein) were present at lower levels in thriving EPT infants than in FT infants which in turn were lower than adult levels (see Figure 1). The mean factor $\mathrm{V}$ level in group $\mathbf{l}$ is lower than that found in fullterm infants. AT-III activity and antigen were present at significantly lower levels in group 1 infants than FT infants. All thriving EPT infants had FDP of 10 or less $\mu \mathrm{g} / \mathrm{ml}$; the normal adult value for this determination is $0-7.5 \mu \mathrm{g} / \mathrm{ml}$. Group 1 had significantly higher factor VIII antigen to factor VIII activity ratios than FT or adults (see Figure 2). The mean factor VIII activity was lower and the mean factor VIII antigen higher in thriving EPT infants than FT infants.

Results of coagulation studies of thriving EPT infants (group 1) compared to unwell EPT infants (group 2), thriving SGA EPT infants (group 2), and severely ill EPT infants (group 3 ) are given in Table 4. There was significant difference between group $I$ and group 3 infants in the screening coagulation tests: PT $(P=<$ $0.01)$, PTT $(P=0.0125)$, TT $(P=0.05)$, and fibrinogen $(P=$ $0.025)$. The screening coagulation tests of group 2 thriving SGA infants were not significantly different from those of group 1. When the results of the group 2 unwell infants were compared to group 1 , their PTs were significantly prolonged $(P=0.01)$, but their PTTs and TTs were not different. The group 2 unwell infants had PTTs shorter than group 3 infants $(P=0.0125)$, but their PT, TT, and fibrinogen were not significantly different. No significant differences were found in the platelet counts of the three groups. Three infants in group 2 had thrombocytopenia. Three infants in group 1, six other infants in group 2 (four SGA) and five group 3 infants developed thrombocytopenia subsequently. In contrast to the thriving EPT infants, two group 2 and one group 3 infants had FDP greater than $10 \mu \mathrm{g} / \mathrm{ml}$. Antithrombin III activity and antigen measurements and assays from the vitamin $\mathrm{K}$-dependent factors (II, VII, VII-X) (Table 4) and the contact factors (XI, XII, high molecular weight kininogen, and prekallikrein) (Figure 1) were the same in all three groups. Factor $\mathrm{V}$ was significantly lower in group 3 than group 1 infants $(P=0.025)$. Thriving $S G A$ infants had levels of factor $V$ similar to group 1 infants. Unwell group 2 infants had levels similar to group 3 infants. There was no significant difference in the three groups for factor VIII procoagulant activity whether measured by PTT or TGT assay (Figure 2 ). However, values for factor VIII antigen were significantly higher in group 3 than group 1 infants $(P=<0.01)$. The ratios of factor VIII antigen to factor VIII activity were significantly increased in the severely ill EPT infants $(P=0.025)$. The ratios of thriving SGA infants were not significantly higher than group I infants. Thus, in group 3 infants factors I and V were significantly 
Table 2. Clinical description of mothers and infants studied

\begin{tabular}{|c|c|c|c|c|c|c|c|}
\hline $\begin{array}{c}\text { Case } \\
\text { no. }\end{array}$ & $\begin{array}{c}\text { Gesta- } \\
\text { tional } \\
\text { age }\end{array}$ & $\begin{array}{c}\text { Birth } \\
\text { weight }\end{array}$ & 5' Apgar & $\begin{array}{c}\text { Clinical } \\
\text { score }\end{array}$ & $\begin{array}{c}\text { Infant } \\
\text { complications } \\
\end{array}$ & $\begin{array}{c}\text { Maternal } \\
\text { complications } \\
\end{array}$ & Delivery $^{3}$ \\
\hline 1 & 28 & 1040 & 8 & 0 & & & v. \\
\hline 2 & 29 & 1580 & 7 & 0 & & & V. \\
\hline 3 & 26 & 740 & 7 & 0 & HMD & & C.S. \\
\hline 4 & 27 & 1000 & 8 & 1 & & Twin & v. \\
\hline 5 & 27 & 787 & 7 & $\mathbf{0}$ & & $20 \%$ Abruptio & v. \\
\hline 6 & 29 & 1138 & 8 & 0 & HMD & Placenta Previa & C.S. \\
\hline 7 & 29 & 1140 & 7 & 0 & HMD & ECL & C.S. \\
\hline 8 & 27 & 1090 & 7 & 0 & HMD & Twin & C.S. \\
\hline 9 & 27 & 1050 & 8 & 0 & HMD & & v. \\
\hline 10 & 29 & 1040 & 8 & 0 & & PROM, $\Delta^{2}$ BLEED & v. \\
\hline 11 & 30 & 750 & 8 & 0 & SGA, NEC, HMD & $\Delta^{2}$ BLEED & v. \\
\hline 12 & 30 & 730 & 8 & 5 & SGA, P-DAY 6, HMD & PROM, Endometritis & v. \\
\hline 13 & 30 & 1372 & 6 & 3 & لB.P., P-DAY ${ }_{36}$ HMD & Fever & C.S. \\
\hline 14 & 27 & 1154 & 5 & 2 & & Twin & C.S. \\
\hline 15 & 31 & 1080 & 5 & 1 & SGA, Sepsis-Day 7 & ECL & C.S. \\
\hline 16 & 27 & 1015 & 6 & 4 & & PROM & v. \\
\hline $17^{4}$ & 31 & 690 & 5 & 3 & SGA, NEC & ECL & C.S. \\
\hline 18 & 30 & 980 & 7 & 1 & SGA, P-DAY $6, H, \mathrm{DM}$ & & C.S. \\
\hline 19 & 31 & 1280 & 4 & 4 & & PROM, Chorioamnionitis & C.S. \\
\hline 20 & 30 & 680 & 5 & 0 & SGA, P-DAY ${ }_{19}$, HMD & Twin & v. \\
\hline $21^{5}$ & 30 & 680 & 6 & 1 & SGA, PH, IVH, DIC, HMD & Twin & C.S. \\
\hline 22 & 31 & 690 & 6 & 1 & SGA, P-DAY ${ }_{37}, \mathrm{HC}$ & PRE-ECL, UTI & C.S. \\
\hline 23 & 24 & 620 & 5 & 3 & Died-9 $9^{\circ}$, HMD & Amnionitis & V. \\
\hline 24 & 31 & 1220 & 7 & 3 & Severe Acidosis, Died- $42^{\circ}, \mathrm{HMD}$ & $\Delta^{3}$ BLEED & V. \\
\hline 25 & 28 & 915 & 4 & 5 & Severe $\downarrow$ B.P., Died-58 ${ }^{\circ}$, HMD & ECL & C.S. \\
\hline 26 & 29 & 1170 & 1 & 5 & Trauma, Died-95 ${ }^{\circ}$ & Iritis, PROM, $\Delta^{1}$ Bleed & v. \\
\hline 27 & 30 & 1190 & 7 & 4 & ICH, HMD Died $-62^{\circ}$ & & v. \\
\hline 28 & 27 & 1005 & 5 & 0 & PDA, IVH, HMD Died- $81^{\circ}$ & Twin & C.S. \\
\hline 29 & 29 & 1233 & 5 & 6 & PFC, Died-27 $7^{\circ}$ HMD & Amnionitis & V. \\
\hline 30 & 30 & 1100 & 2 & 6 & Dysmorphic, Died-15, HMD & PROM, Chronic Abruptio & v. \\
\hline
\end{tabular}

' $P=$ pneumonia; $S G A=$ small for gestational age; NEC = necrotizing enterocolitis; $\downarrow B . P$. $=$ hypotension; $P H=$ pulmonary hemorrhage; $I V H=$ intraventricular hemorrhage; $D I C=$ disseminated intravascular coagulation; $H C=$ hydrocephalus; $I C H=$ intracranial hemorrhage $o=$ hours of age; $P F C=$ persistent fetal circulation; $H M D=$ hyaline membrane disease.

${ }^{2} E C L=$ eclampsia; $\triangle=$ trimester; $P R O M=$ prolonged ruptured membranes greater than $24 \mathrm{hr} ; U T I=$ urinary tract infection.

${ }^{3} V=$ vaginal; $C . S .=$ caesarian section.

${ }^{4}$ Died at day 13.

"Died at day 15.

Table 3. Autopsy results

\begin{tabular}{cc}
$\begin{array}{c}\text { Case } \\
\text { No. }\end{array}$ & \\
\hline 17 & $\begin{array}{c}\text { Hyaline membrane disease, cerebral petechiae, pulmonary hem- } \\
\text { orrhage-focal. } \\
\text { Hyaline membrane disease, intracranial hemorrhage, dissemi- } \\
\text { nated intravascular coagulation, pulmonary hemorrhage. }\end{array}$ \\
$21^{\prime}$ & $\begin{array}{c}\text { Hyaline membrane disease, chorioamnionitis. } \\
\text { Hyaline membrane disease, intraventricular hemorrhage, pul- } \\
\text { monary hemorrhage-focal. }\end{array}$ \\
24 & $\begin{array}{c}\text { Hyaline membrane disease, pulmonary hemorrhage-focal, sub- } \\
\text { arachnoid hemorrhage, intraventricular hemorrhage, perito- }\end{array}$ \\
neal hematoma, subcapsular liver hematoma. \\
27 & $\begin{array}{c}\text { Intracranial hemorrhage. } \\
\text { Hyaline membrane disease, intraventricular hemorrhage. }\end{array}$ \\
28 & $\begin{array}{c}\text { Hyaline membrane disease, small pulmonary artery thrombi. } \\
\text { Hyaline membrane disease, pulmonary hemorrhage-focal, deci- } \\
\text { duitis, focal cystic lesion of lung, dysmorphism. }\end{array}$ \\
\hline
\end{tabular}

' Autopsy not performed, clinical diagnosis.

lower, the VIII antigen/activity ratio higher and platelets, factors II and VII were no different than in group 1 infants.

\section{DISCUSSION}

In this study, the 10 thriving EPT infants were carefully chosen from the 30 infants studied after consideration of influencing factors. The effect of maternal complications on infant coagulation parameters is difficult to assess. No personal history of hematologic or coagulation abnormalities was present in any of the infants' mothers. Family history was also negative. Only the mothers of cases 15,17 , and 25 were thrombocytopenic at the time of delivery. Although coagulation abnormalities have been reported in infants of mothers with preeclampsia (47), the infant's condition at birth is probably the most important determinant of these changes. Case 7 was vigorous and had an uneventful perinatal course in spite of his mother's severe preeclampsia. Abruptio placenta does not appear to effect the hemostatic mechanisms of the newborn unless the area of abruption is greater than $20 \%$ of the placental surface (49), a condition that was not present in the placenta of any of the infants studied. None of the mothers of infants in this study received long term diuretic (33), antiinflammatory $(60)$, xanthine $(42)$, anticoagulant $(28,45)$, or anticonvulsant therapy (58). Ingestion of aspirin or aspirin-containing products for the wk before delivery was denied by all mothers except cases 1,4 , and 20 . Although maternal aspirin ingestion may alter her infant's platelet function and increase susceptibility to bleeding $(7,14)$, cases 1 and 4 were included in the thriving EPT infants because platelet function was not part of this study and neither infant had clinical signs of bleeding. The mothers of cases $6,7,9$, $12,13,15,16,19,20-22,29$, and 30 were on antibiotic therapy at the time of delivery. Cases 6,7 , and 9 had no clinical or laboratory signs of infection during the first $72 \mathrm{hr}$ of life and, therefore, were included in group 1.

Because infants of diabetic mothers (48) and infants with $R h$ 
Table 4. Coagulation results

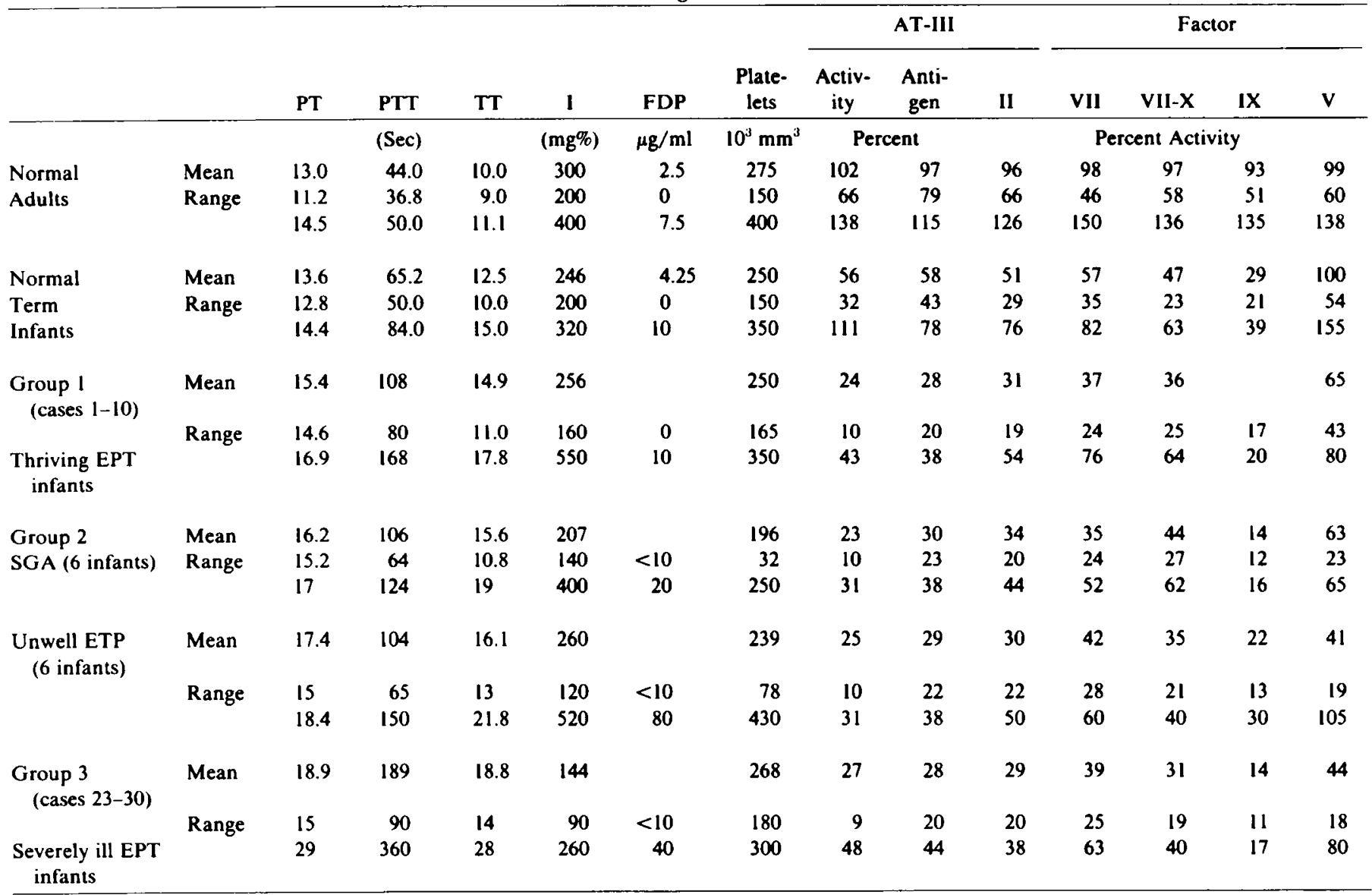

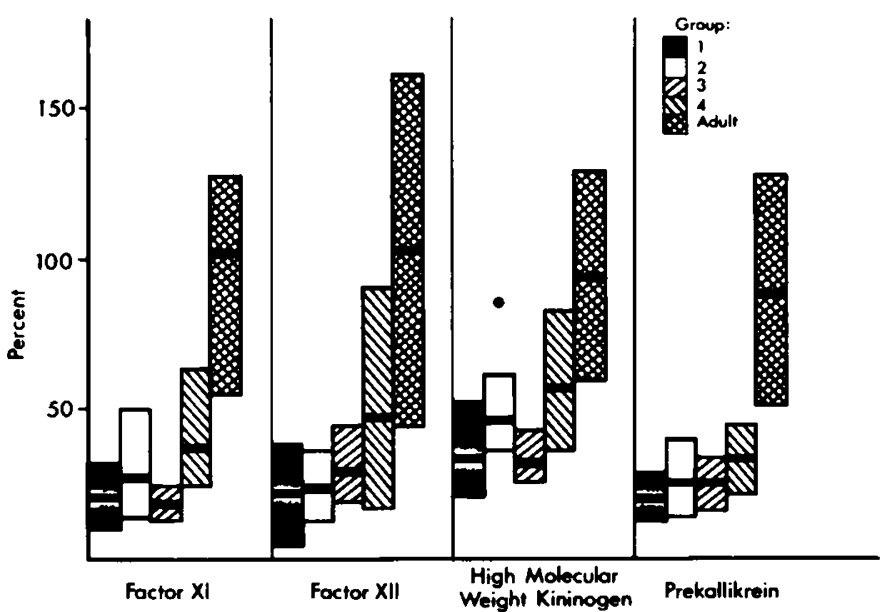

Fig. 1. The mean (horizontal bar) and range for percent clotting activity of contact coagulation factors are shown for each study group. Group 1: thriving EPT infants; group 2: moderately ill EPT infants; group 3: severely ill EPT infants; group 4: normal term infants.

sensitization $(11,50)$ have associated coagulation abnormalities which may represent an integral part of the pathophysiology of their primary disease, such infants were not included in this study. Infants with hyaline membrane disease (HMD) were included in the thriving infant group if they were otherwise healthy. Although it has been suggested that HMD could be secondary to disseminated intravascular coagulation (DIC) (59), most studies $(3,13$, $43,44)$ suggest that the coagulation changes associated with HMD were a function of severity of illness rather than the specific diagnostic entity. In this study, there was no statistical difference in the coagulation studies of infants with or without HMD when

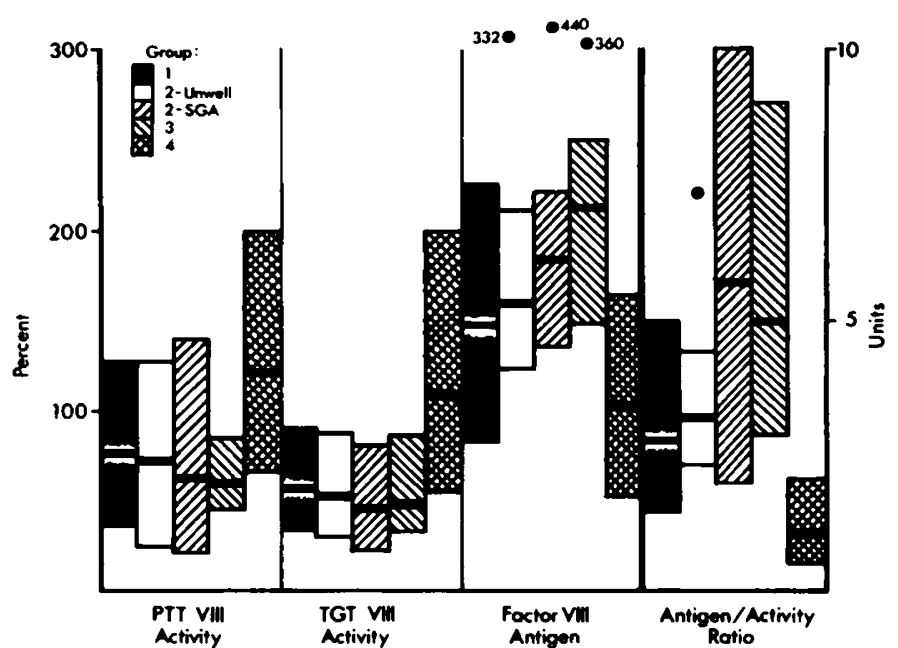

Fig. 2. The mean (horizontal bar) and range for percent factor VIII as measured by PTT (one stage) VIII assay, TGT (two stage) VIII assay, and immunologic (antigen) assay are shown for each study group. Also, the factor VIII antigen to factor VIII activity (TGT-VIII assay) ratio is shown in units on the right. Group 1: thriving extremely premature (EPT) infants; group 2: moderately ill EPT infants; group 3: severely ill EPT infants; group 4: normal term infants.

grouped according to clinical status. SGA infants were placed in the unwell group because of their higher morbidity and mortality when compared to appropriate for gestational age EPT (39). Birth asphyxia $(4,5,12,20,46,63)$, hypothermia $(10,34)$, hypoxia $(55$, $61)$, acidosis $(16,19)$, hypotension, and sepsis $(2,54)$ have been associated with clotting abnormalities in neonates. Infants with the above problems were not included in group 1 . 
Evidence of developmental evolution of coagulation can be seen when the studies of the 10 thriving EPT are compared to normal full-term infants (Table 4). The PT, PTT, and TT all became shorter with increasing gestational age which suggested intrauterine maturation of coagulation factors. In agreement with previous studies $(24,31,32)$, the gestational age dependency of the vitamin K-dependent factors (II, VII, IX, X) after age of viability ( $24 \mathrm{wk})$ is confirmed. Also, as previously cited in the literature $(21,57)$, fibrinogen levels and platelet counts in the thriving EPT infants are comparable to term infant and adult values. FDP of $10 \mu \mathrm{g} / \mathrm{ml}$ or less were found in the thriving EPT; similar values have been seen in other normal preterm and term infants (24).

The opportunity to study thriving EPT infants allowed new data to be obtained for antithrombin III-heparin cofactor, the contact factors, and factor VIII antigen. The AT-III antigen results in this study agree well with those previously found using capillary blood in the extremely premature infants (23). When compared to healthy FT infants, there is a definite gestational dependency of AT-III levels. AT-III measurements in thriving EPT infants were decreased to below those found in hereditary AT-III deficiency $(26-56 \%)(23)$ and may help to explain the susceptibility to thrombosis seen in extremely premature neonates.

The procoagulant activity of contact factors XI, XII, high molecular weight kininogen (Fitzgerald factor), and prekallikrein (Fletcher factor) are all markedly decreased in thriving EPT infants (Figure 1). They are related to gestational age with further postnatal maturation before reaching adult values. The combined deficiency of these factors probably contributes to the prolonged PTT of the EPT infants. Contact factor dependent pathways have been related to mechanisms of inflammation (37). Whether the deficit of contact factors in the newborn infant contributes to their susceptibility to infection remains to be determined.

Fetuses have had both factor VIII activity and antigens measured. Factor VIII activity levels of 12- to 24-week fetuses by PTT assay showed a mean of $52 \%(23-112 \%)$ and antigen levels had a mean of $70 \%(23-134 \%)(31)$. As suggested by Sell and Corrigan (57) who found factor VIII activity by PTT assay of $90 \pm 15 \%$ in EPT infants, this study confirms a gestational age dependency of factor VIII activity (Figure 2). The factor VIII activity values obtained by PTT assay and TGT assay in the thriving EPT infants agreed closely (correlation coefficient of 0.9 ). The ratio of factor VIII antigen to factor VIII activity is markedly increased ( $2.8 \mathrm{vs}$. 1.01 in FT and adults). Increased ratios have been reported in adults in late pregnancy (6), after labor (6), in DIC (17), and in liver disease $(30,41)$. Interpretation of these data have included release of a dysfunctional protein, increased endothelial release of antigen, impaired catabolism of antigen, or accelerated destruction of coagulant perhaps secondary to thrombin or plasmin release. An additional explanation for the increased antigen level measured by immunoelectrophoresis may be due to in vitro artifact caused by unfolding of the molecule exposing more antigenic sites. Henriksson and Holmberg (27), studied sick newborns in whom factor VIII was measured by PTT assay and immunologic technique. Included in this study were 12 infants of gestational age varying from $26-40 \mathrm{wk}$. Their clinical diagnoses included infant respiratory distress syndrome, respiratory distress syndrome, apnea, or asphyxia. Lower factor VIII coagulant activities were found than antigen measurements. The mean ratio of factor VIII antigen to activity in their series was 3.2 (range 1.1-13.4); infants who died had a mean ratio of 3.8 (range 1.1-13.4). In their normal full-term infants, the mean ratio was 1.01 . This altered ratio was attributed to low grade pathologic proteolysis secondary to plasmin or thrombin release, although no alteration of factor VIII antigen in the two infants studied by crossed immunoelectrophoresis was seen. The present study (Figure 2) suggests that because of the high antigen to activity ratio seen in thriving EPT infants, a dysfunctional or fetal factor VIII may have been produced. However, the further elevation of this ratio in the severely ill EPT infants is in keeping with a pathologic proteolysis or increased endothelial release of factor VIII antigen. This hypothesis is further strengthened by the mean ratio of factor VIII antigen to activity found in the 12 to 24-week fetus of 1.3 (31) which suggests a postnatal change rather than one related to gestational development.

In this study, thriving SGA infants had coagulation studies which were not statistically different from those of thriving EPT infants. This finding agrees with the report of Jensen $e t$ al. (32) who studied SGA infants of 33-37 wk of gestational age. Case 22 was thrombocytopenic at the time of study. She was an infant who had petechiae at birth and was suspected clinically of having a congenital intrauterine infection. Four other thriving SGA infants subsequently became thrombocytopenic. Others (22) have reported thrombocytopenia in SGA infants.

Group 3, the severely ill infants, had prolongations of their PT, PTT, and TT with decreased levels of fibrinogen and factor V. As in the group 2 unwell infants, this PTT prolongation cannot be explained by differences from group 1 in contact factor levels of factor VIIl activity measurements. Contact factors were unaffected in these seriously ill infants, a finding previously documented for factor XII (15). An elevation of factor VIII antigen/activity was noted in these severely ill infants $(P=0.025)$ when compared to the thriving EPT infants. Thus, the coagulation changes which occurred in severely ill EPT infants were mainly in the factors which would be altered during intravascular coagulation or pathologic proteolysis (26), factors I, V, and VIII. Increased fibrinogen turnover in the preterm infant has been shown previously (35). The absence of thrombocytopenia or FDP does not rule out an intravascular consumptive process $(15,22)$. The prolongation of the PTT, PT, and TT could be related to increased levels of fibrin monomer or soluble fibrin-fibrinogen complexes (which would not be measured by the serum FDP test). Unfortunately, specific tests for fibrin monomer were not done.

The clinical complications (Table 2) and the autopsy results (Table 3 ) indicate a high incidence of hemorrhagic and thrombotic complications in the group of infants studied (pulmonary hemorrhage, intraventricular hemorrhage, DIC, hematoma of the liver, necrotizing enterolitis arterial thrombi). Although it was not the purpose of this study to study coagulation changes serially, it is interesting to note the relative normality of the initial clotting tests (platelets, fibrinogen, K-dependent factors, factors VIII and V) in the thriving EPT infants as compared to term infants. Deterioration of the coagulation status occurs quickly in the sick infant and must be considered an important contributing factor to the bleeding diatheses seen.

\section{REFERENCES AND NOTES}

I. Abilgaard, C. F., Simone, J. V.. and Vanderheiden. J.: A semiautomatic one stage factor ViII assay. J. Lab. Clin. Med.. 69: 706 (1967)

2. Alebouyeh, M., Remien. A.. and Marget. W.: Incidence of disseminated intravascular coagulation in the course of septicemia in newborn infants. $Z$. Kinder. I109: 326 (1971).

3. Altstatt. L. B. Dennis, L. H. Sundell, H.. Malan. A.. Harrison. V., Hedvall, G. Eichelberger. J., Fogel. B.. and Stahlman. M.: Disseminated intravascular coagulation and hyaline membrane disease. Biol. Neonate. 19: 227 (1971).

4. Anderson. J. M.. Brown, J. K., and Cockburn, F.: On the role of disseminated intravascular coagulation in the pathology of birth asphyxia. Develop. Med. Child Neurol.. 16: 581 (1974).

5. Appleyard. W. J.. and Cottom. D. G.: Effect of asphyxia on thrombotest values in low birthweight infants. Arch. Dis. Child., 45: 705 (1970).

6. Bennett. B., Oxnard. S. C.. Douglas, A. S., and Ratnoff. O. D.: Studies on antihemophilic factor (AHF, factor VIII) during labor in normal women. in patients with premature separation of the placenta. and in a patient with von Willebrand's disease. J. Lab. Clin. Med.. 84: 851 (1974).

7. Bleyer. W. A., and Breckenridge. R. T.: Studies on the detection of adverse drug reactions in the newborn. JAMA, 213: 2049 (1970).

8. Borchgrevinck. C. F., Pool. J. G., and Stormorken, H.: Factor V assay. J. Lab. Clin. Med., 55: 625 (1960).

9. Brazie. J. V., and Lubchenco, L. O.: Current Pediatric Diagnosis and Treatment. p. 40 (Los Altos. California. Lange Medical Publishers, 1974).

10. Chadd, M. A.. and Gray. O. P.: Hypothermia and coagulation defects in the newborn. Arch. Dis. Child.. 47: 819 (1972).

11. Chessells. J. M., and Wigglesworth. J. S.: Haemostatic failure in babies with Rhesus isoimmunization. Arch. Dis. Child.. 46: 38 (1971).

12. Chessells, J. M.. and Wigglesworth, J. S.: Coagulation studies in severe birth asphyxia. Arch. Dis. Child., 46: 253 (1971).

13. Chessells, J. M., and Wigglesworth. J. S.: Coagulation studies in preterm infants 
with respiratory distress and intracranial haemorrhage. Arch. Dis. Child., 47: 564 (1972).

14. Corby, D. G., and Schulman. I.: The effects of antenatal drug administration on aggregation of platelets of newborn infants. J. Pediatr.. 79: 307 (1971).

15. Corrigan, J. J., Sell, E. J., and Page. L. C.: Hageman factor and disseminated intravascular coagulation (DIC) in newborns and rabbits. Pediatr. Res.. II: 916 (1977).

16. Crowell, J. W., and Houston, B.: Effect of acidity on blood coagulation. Am. J. Phys., 201: 379 (1961).

17. Denson, K. W. E.: The ratio of factor VIII-related antigen and factor VIII biological activity as an index of hypercoagulability and intravascular clotting. Thrombos. Res., 10: 107 (1977).

18. Ekelund, H., and Finnstrom, O.: Fibrinolysis in preterm infants and in infants small for gestational age. Acta Paediatr. Scand., 61: 185 (1972).

19. Hardaway, R. M., Elovitz. M. J., Brewster, Jr., W. R., and Houchin, D. N.: Clotting time of heparinized blood. Arch. Surg., 89: 701 (1964)

20. Hathaway, W. E., Mahasandana. C., and Makowski, E. L.: Cord blood coagulation studies in infants of high-risk pregnant women. Am. J. Obstet. Gynecol., 121: 51 (1975)

21. Hathaway. W. E.: The bleeding newborn. Semin. Hematol, 12: 175 (1975).

22. Hathaway, W. E., and Bonnar, J.: Perinatal Coagulation. (Grune and Stratton. New York. 1978)

23. Hathaway, W. E., Neumann, L. L., Borden, C. A., and Jacobson. L. J.: Immunologic studies of antithrombin III-heparin cofactor in the newborn. Thrombos. Hemostasis, 39: 624 (1978).

24. Heikinheimo, R.: Coagulation studies with fetal blood. Biol. Neonate, 7: 319 (1964).

25. Henderson, E. S., and Rapaport, S. 1.: The thrombotic activity of activation product. J. Clin. Invest., 41: 235 (1962).

26. Henriksson, P.. and Ekelund. H.: Abnormal proteolysis in sick newborns. Acta Paediatr. Scand., 64: 327 (1975).

27. Henriksson. P.. and Holmberg. L.: Factor VIII activity and antigen in sick newborns with pathological proteolysis in blood. Acta Paediatr. Scand.. 67: 83 (1978).

28. Hirsh, J., Cade, J. F., and O'Sullivan, E. F.: Clinical experience with anticoagulant therapy during pregnancy. Br. Med. J., $1: 270$ (1970).

29. Hjort, P., Rapaport, S. I., and Owren, P. A.: A simple specific one step prothrombin assay using Russell's viper venom in cephalin suspension. J. Lab. Clin. Med., 46: 89 (1955).

30. Holmberg, L.. and Nilsson, I. M.: AHF related protein in clinical praxis. Scand. J. Haematol., 12: 221 (1974).

31. Holmberg, L., Henriksson, P., Ekelund, H., and Astedt. B.: Coagulation in the human fetus. Comparison with term newborn infants. J. Pediatr., 85: 860 (1974).

32. Jensen, A. H-B., Josso, F., Zamet, P.. Monset-Couchard, M., Minkowski. A.: Evolution of blood clotting factor levels in premature infants during the first 10 days of life: a study of 96 cases with comparison between clinical status and blood clotting factor levels. Pediatr. Res., 7: 638 (1973)

33. Jerkner. K., Kutti. J., and Victorin, L.: Platelet counts in mothers and their newborn infants with respect to antepartum administration of oral diuretics. Acta Med. Scand., 194: 473 (1973).

34. Johansson, B. W., and Nilsson, I. M.: The effect of heparin and e-aminocaproic acid on the coagulation in hypothermic dogs. Acta Physiol. Scand., 60: 267 (1964).

35. Karitzky, D., Kleine, N., Pringsheim, W., and Kunzer. W.: Fibrinogen turnover in the premature infant with and without idiopathic respiratory distress syndrome. Acta Paediatr. Scnad., 60: 465 (1971).

36. Laurell, C. B.: Electroimmunoassay. Scand. J. Clin. Lab. Invest., 29: (Suppl. 124) 21 (1972).

37. Lepow, I. H., Ward, P. A.: Inflammation: Mechanisms and Control. (Academic Press, New York, 1972).

38. Lubchenco, L. O.. Hansman, C., and Boyd, E.: Colorado intrauterine growth charts. Pediatrics, 37: 403 (1966).

39. Lubchenco, L. O., Searls, D. T., and Brazic. J. V.: Newborn classification of neonatal mortality risk. J. Pediatr., 81: 814 (1972).

40. Mahasandana, C., and Hathaway, W. E.: Circulating anticoagulants in the newborn: relation to hypercoagulability and the respiratory distress syndrome. Pediatr. Res., 7: 670 (1973).

41. Maisonneuve, P., and Sultan, Y.: Modification of factor VIII complex properties in patients with liver disease. J. Clin. Pathol., 30: 221 (1977).
42. Manku. M. S., and Horrobin, D. F.: Chloroquine, quinine, procaine, quinidine. tricyclic antidepressants, and methylxanthines as prostaglandin agonists and antagonists. Lancet. 2: 1115 (1976)

43. Margolis, C. Z.. Orzalesi, M. M.. and Schwartz. A. D.: Disseminated intravascular coagulation in the respiratory distress syndrome. Am. J. Dis. Child., 125: 324 (1973)

44. Markarian, M., Lubchenco, L. O., Rosenblut, E., Fernandez, F., Lang. D. Jackson, J. J., Bannon, A. E., Lindley, A., Githens, J. H., and Martorell, R.: Hypercoagulability in premature infants with special reference to the respiratory distress syndrome and hemorrhage. II. The effect of heparin. Biol. Neonate, 17: 98 (1971)

45. Mountain, K. R., Hirsh, J.. and Gallus, A. S.: Neonatal coagulation defect due to anticonvulsant drug treatment in pregnancy. Lancet I: 265 (1970)

46. Muntean, W., and Muller. W. D.: Gerinnungsuntersuchungen aus kapillarbiut bei neugeborenin. Helv. Paediatr. Acta, 31: 149 (1976).

47. Nielsen, N. C.: Influence of preeclampsia upon coagulation and fibrinolysis in women and their newborn infants immediately after delivery. Acta Obstet. Gynecol. Scand., 48: 523 (1969).

48. Nielsen. N. C.: Coagulation and fibrinolysis in diabetic women immediately postpartum and in their newborn infants. Influence of caesarean section. Acta Obstet. Gynecol. Scand., 48: 392 (1969).

49. Nielsen, N. C.: Coagulation and fibrinolysis in mothers and their newborn infants following premature separation of the placenta. Acta Obstet. Gynecol. Scand. 49: 77 (1970).

50. Nielsen, N. C.: Coagulation and fibrinolysis in Rhesus-immunized mothers and their erythroblastotic newborn infants. Acta Obstet. Gynecol. Scand., 49: 61 (1970).

51. Owren. P. A., and Aas. K.: The control of dicoumarol therapy and the quantitative determination of prothrombin and proconvertin. Scand. J. Clin. Lab. Invest. 3: 201 (1951).

52. Pool, J. G., and Robinson, N.: Assay of plasma antihemophiliac globulin (AHG) Br. J. Hematol., 5: 17 (1959).

53. Proctor, R. R., and Rapaport, S. E.: The partial thromboplastin time with kao lin. Am. J. Clin. Pathol., 36: 212 (1961).

54. Relier, J. P., de Gamarra, E., de Bethmann, O., Savaglio, N., and Minkowski, A.: Interet de la mesure du taux de fibrinogene dans les infections neonatales par contamination maternelle. Arch Franc. Ped., 33: 109 (1976).

55. Rogner, G., Maak. B., and Frenzel. J.: Das verhalten der gerinnungsfaktoren bei hypoxischen neugeborenen unter der puffertherapie. Zeits. fur Kinder., 104: 218 (1968)

56. Searcy, R. L.. Simms, M. M.. and Low, M. Y.: A simple method for rapid detection of hypofibrinogenemia. Am. J. Med. Tech., 33: 27 (1967).

57. Sell, E. J., Corrigan. Jr., J. J.: Platelet counts, fibrinogen concentrations, and factor V and factor VIII levels in healthy infants according to gestational age. J. Pediatr.. 82: 1028 (1973).

58. Solomon. G. E., Hilgartner. M. W., and Kutt. H.: Coagulation defects caused by diphenylhydantoin. Neurology, 22: 1165 (1972).

59. Stark, C. R., Abramson, D.. and Erkan. V.: Intravascular coagulation and hyaline-membrane disease of the newborn. Lancet. 1 : 1180 (1968).

60. Turbeville. D. F.: Letter to the Editor. J. Pediatr., 85: 737 (1974).

61. von Creveld, A., Paulssen. M. M. P., and Teng. S. K.: Prothrombin and accelerator globulin in the plasma of newborns under normal and pathological conditions. Etudes Neonataie, 1: 87 (1952).

62. vonKaulla, K. N., and vonKaulla. E.: Estimation of thrombin time of plasma. Blood coagulation, hemorrhage and thrombosis. p. 334 (Grune and Stratton. London, 1964).

63. Weissbach, G., and Lenk, H.: Defibrinierungssyndrome bei neugeborenen. Helv. Pediatr. Acta, 26: 78 (1971)

64. The authors thank Dr. Robert Waldman for the generous supply of Fitzgeralddeficient plasma.

65. Dr. Michael A. Simmons is an Established Investigator of the American Heart Association.

66. This research was supported, in part, by United States Public Health Service grants no. HL20337 and HL18507.

67. Requests for reprints should be addressed to: William E. Hathaway M.D. Department of Pediatrics, University of Colorado Medical Center, 4200 East Ninth Avenue, Denver, Colorado 80262, USA.

68. Received for publication August 28, 1978

69. Accepted for publication January 11, 1979 